\title{
Investigation on Microwave Energy Attenuation into the Epoxy Glass Thick Parts with Curve-Shaped Geometry
}

\author{
Lyes Douadji ${ }^{1}$, weiwei Du ${ }^{2, *}$, Fethi Benkhenadou ${ }^{3}$, Wen Shi ${ }^{1}$ and Siyu Jin ${ }^{1}$ \\ ${ }^{1}$ Chongqing Academy of Science \& Technology, Research Center for Advanced Materials, 2 Yangliu Road, Huang shan Avenue, \\ New North Zone, Chongqing 401123, China \\ ${ }^{2}$ Southwest University, College of Material Science and Engineering; 2 Tiansheng Road, BeiBei District, Chongqing 400715, \\ China \\ ${ }^{3}$ Department of Physics, Faculty of Sciences, University of Tlemcen, PO Box.119, Tlemcen 13100, Algeria \\ ${ }^{*}$ Corresponding author
}

\begin{abstract}
The major problem in microwave processing is attenuation of microwave heating source. This work is investigation by simulation on the microwave energy attenuation into the long and thick parts with curve-shaped geometry. Physical properties of final products to be manufactured, in particular the mechanical properties, are directly dependent on uniform repartition of microwave source heating during the treatment. We propose Dielectric Effect of Attenuation Inversion of the Electromagnetic Waves (DEAI) as solution for uniform treatment long and thick parts with curve-shaped geometry with epoxy glass by microwave energy. This solution utilizes dielectric properties of the mold to control the microwave heat source attenuation into the composite to be treated. Electromagnetic modelling of microwave process was carried out by FEMLAB software using finite element. The results show that microwave source heating attenuation into the parts with curve-shaped geometry is important compared with parallelepiped geometry. This attenuation we can controls and inverse it in the propagation direction.
\end{abstract}

Keywords-microwave process; attenuation problem; microwave energy; curve- shaped geometry; epoxy Glass

\section{INTRODUCTION}

Polymeric materials are usually low in thermal conductivity and high in thermal degradability. These characteristics limit the possible temperature rise and hence the possible reduction of the production time. Application of internal thermal sources (microwave energy) created by the dielectric hysteresis phenomenon offers an alternative. Because; the volume heated isn't dependent on heat transfer by conduction or convection. Microwave heating can generate higher power density then conventional heating methods, enabling increased production speeds and decreased production costs without risk to overheat the surface of materials [1]. By using industrial microwave systems for heating combustible gaseous by-products can be avoided, thus eliminating the need for environmental permits and improving working conditions. In addition; microwave heating systems can be $50 \%$ or more efficient than conventional systems, leading to major savings in energy consumption and cost.
The attenuation of microwave source heat into long parts is the major problem of a microwave process [2]. To ensure uniform treatment by microwave energy, the attenuation problem should be solved. Many research works have been carried out on the use of microwave energy for manufacturing process of polymer composite parts, e.g., polymerization of thermosetting matrices. Morey [3] and Kawasa et al. [4] reported manufacturing of composite parts by microwave energy. Ono et al. [5] and Wilson et al. [6] Studied crosslinking of different composites using microwaves energy. Jullien et al. [7] and Aussudre et al. [8] investigated relationship between microwave processing parameters and properties of the final products. There are only a few research papers, however, focused on issues of attenuation and uniform treatment by microwave energy of long composite parts [9-13]. In this paper, we propose Dielectric Effect of Attenuation Inversion of the Electromagnetic Waves (DEAI) developed by DOUADJI and DELMOTTE as a new way for uniform treatment of epoxy glass by microwave energy. This solution utilizes the dielectric properties of the mold to control the microwave heat source attenuation into the composite to be treated.

\section{EASE OF Use Microwave Process AND Dielectric EFFECT OF ATTENUATION INVERSION OF THE Electromagnetic WAVES (DEAI)}

The fundamentals of electromagnetic theory, dielectric response and applications of microwave heating on processing of materials especially fiber composites, are reviewed by Thostenson [14]. The process microwaves require a parallelepiped waveguide filled by three dielectrics (figure I) in which one represents the mold of the part to be treated. The aluminium applicator has a parallelepiped form $(0.12 \times 0.25 \mathrm{x}$ $2 \mathrm{~m})$. 


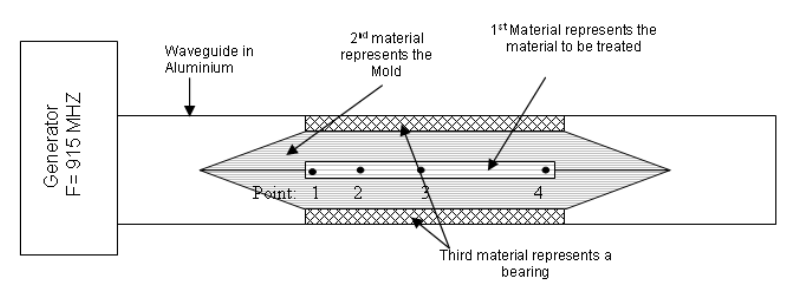

FIGURE I. .PRINCIPAL OF MICROWAVE PROCESS

The results of electromagnetic modelling show that the longitudinal distribution of the electric field in material 1 (part with epoxy glass) strongly depends on the thickness of the mold (material 2). Therefore, the attenuation of the wave intensity in material 1 can be essentially eliminated by the proper variation of the thickness of the dielectric mold along the direction of the electromagnetic wave propagation, as illustrated in Figure II. For specific dimensions of the mold, attenuation in the direction opposite to the electromagnetic propagation was already observed [13].

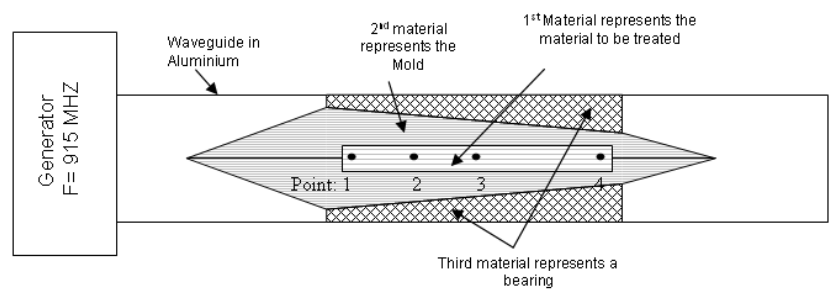

FIGURE II. SOLUTION PROPOSED FOR UNIFORM TREATMENT

The details about the dielectric effect of attenuation inversion of electromagnetic waves (DEAI) are presented by DOUADJI and DELMOTTE in the previous works [13]. DEAI is solution proposed to uniform heating of thick and long parts with epoxy glass. This solution utilizes the dielectric properties of the mold to control the microwave heat source attenuation into the composite to be treated. For uniform treatment of the epoxy glass thick parts with curveshaped geometry, we propose to use DEAI solution. For this reason we propose to change the geometry of the dielectric mould for to adapt it to curve- shaped geometry of part like represented in the figure III and IV.

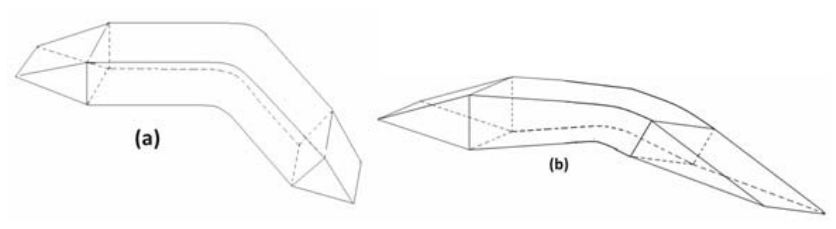

FIGURE III. GEOMETRIES OF THE MOULD FOR CURVE- SHAPED PARTS (A) GEOMETRY OF THE MOULD WITHOUT DAEI; (B) GEOMETRY OF THE MOULD WITH DAEI

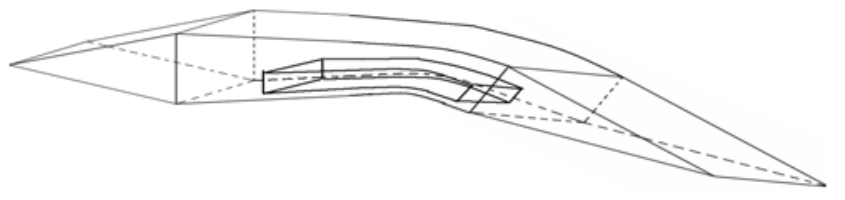

FIGURE IV. MOULD AND CURVE- SHAPED PART

\section{MATERIALS}

The first material is pre-impregnated epoxy glass composite (Vicotex ${ }^{\circledR}$ M10/46\%/664-120cm). The long fibres glass are oriented in one direction and impregnated in an epoxy matrix DGEBA-DDA. The material of the mold is silicon glass composite purchased from Isotac Isolant du SudEst Company. This material surrounds the part in order to obtain an effect of concentration of the waves in the median plane of the applicator. This phenomenon is due to its dielectric properties which are much higher than those of Polyethylene honeycomb. It has a permittivity of about 5 and a characteristic of absorption of about 0.03 . The third material is honeycomb polyethylene with thick of $10 \mathrm{~mm}$. The origin of this material is from NIDAPLAST Composites Company. Since its dielectric properties are close to those of the air ( $\varepsilon^{\prime}=1.1, \varepsilon^{\prime \prime}=0.001$ ), this material interacts little with the waves, absorbs little electromagnetic energy absorption and causes little reflection to the waves. Then, the role of this material is to position the mold (material 2) and the part (material 3) in the median plane of waveguide.

\section{Electromagnetic Modeling}

The electromagnetic modeling is the resolve of wave propagation equation (1) deduced from the Maxwell equations. We used FEMLAB 3.2 software for the electromagnetic field modeling into a waveguide filled with three dielectric materials (mold with silicone glass; part with epoxy glass and bearing with honeycomb polyethylene. The Boundary conditions are detailed in our previous works [10]

$$
\frac{\partial^{2} \mathrm{E}_{\mathrm{x}}}{\partial \mathrm{y} 2}+\frac{\partial^{2} \mathrm{E}_{\mathrm{x}}}{\partial \mathrm{z}^{2}}=\varepsilon \mu \omega 2 \mathrm{E}_{\mathrm{x}}
$$

\section{RESULTS AND DISCUSSION}

Figures $\mathrm{V}$ obtained by FEMLAB software, shows the evolution of electric field along a $10 \mathrm{~mm}$ thick composite part corresponding to the configuration of the figure III. a. The table I is the values of electric field attenuation corresponding to different thickness of the mould. It can be seen from the figure $\mathrm{V}$ and the table 1; that attenuation of microwave energy represented by electric field norm strongly depends on thickness of the mold. According to table I; the attenuation decrease whit the thickness of the mold. This reduction is due to the absorption of microwave energy by the mold. When the mold mass increases, we observed that the energy absorption and the attenuation increases together. The attenuation is positive independent of the mold thickness. 


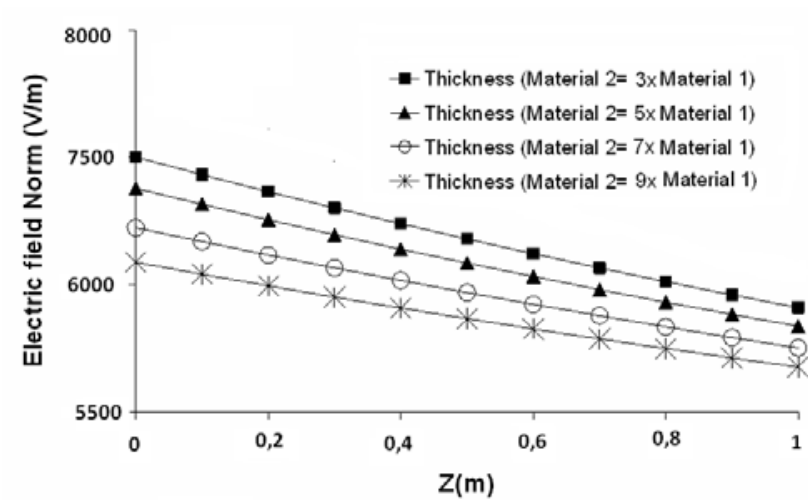

FIGURE V. ELECTRIC FIELD NORM INTO THE MATERIAL TO BE TREATED WITHOUT SOLUTION DAEI AND CORRESPONDING TO THE CONFIGURATION AS SHOWN IN FIGURE III.A

TABLE I. THE VALUES OF ATTENUATION WITH THE THICKNESS OF THE MOULD.

\begin{tabular}{|c|c|c|c|c|}
\hline $\begin{array}{c}\text { Thickness } \\
\text { of the } \\
\text { mould } \\
\text { (mm) }\end{array}$ & $\begin{array}{c}3 \times \text { the } \\
\text { thickness } \\
\text { of the } \\
\text { part }\end{array}$ & $\begin{array}{c}5 \times \text { the } \\
\text { thickness of } \\
\text { the part }\end{array}$ & $\begin{array}{c}7 \times \text { the } \\
\text { thickness of } \\
\text { the part }\end{array}$ & $\begin{array}{c}9 \times \text { the } \\
\text { thickness } \\
\text { of the part }\end{array}$ \\
\hline $\begin{array}{c}\text { Attenuation } \\
\left.\text { ( } \mathbf{m}^{-1}\right)\end{array}$ & 0,37 & 0,35 & 0,30 & 0,28 \\
\hline
\end{tabular}

In contrary, according the figure VI and the table II; the attenuation of microwave source energy depends on dimension of the mold and at specific dimensions the attenuation will be negative. We have called this situation in our previous results: Dielectric Effect of Attenuation Inversion of the Electromagnetic Waves.

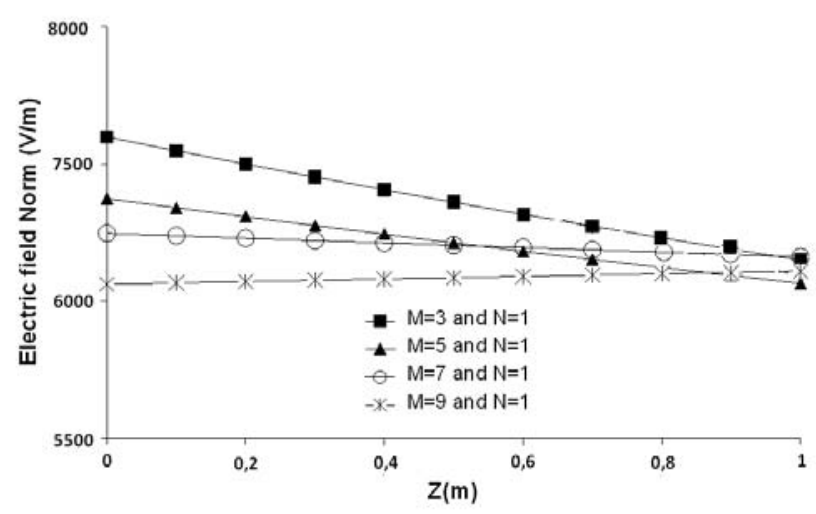

FIGURE VI. ELECTRIC FIELD NORM INTO THE MATERIAL TO BE TREATED CORRESPONDING TO THE CONFIGURATION AS SHOWN IN FIGURE III.B. (M AND N REPRESENT THE RATIOS OF THE THICKNESS OF MOLD AND MATERIAL TO BE TREATED AT THE ENTRANCE AND EXIT OF MATERIAL 1, RESPECTIVELY)

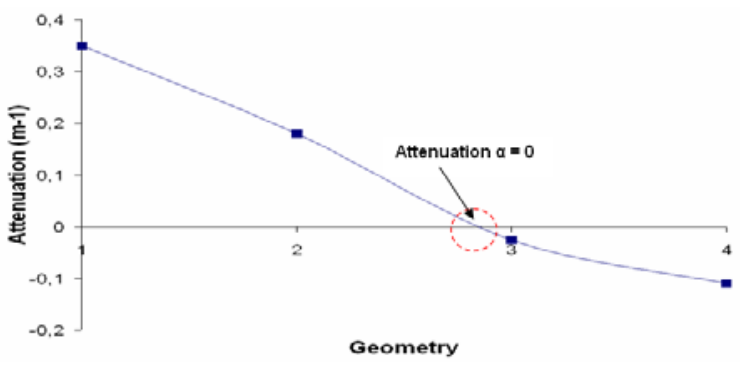

FIGURE VII. THE EVOLUTION OF ATTENUATION WITH THE DIFFERENT THE MOLD GEOMETRIES IN THE TABLE II

The evolution of attenuation with the thickness and dimension of the mold are shown in figures VII. This Figure shows that, at a specific dimension of the mold the attenuation effect can be null.

TABLE II. THE VALUES OF ATTENUATION WITH THE GEOMETRY OF THE MOULD WHICH (M AND N REPRESENT THE RATIOS OF THE THICKNESS OF MOLD AND MATERIAL TO BE TREATED AT THE ENTRANCE AND EXIT OF MATERIAL 1, RESPECTIVELY)

\begin{tabular}{|c|c|c|c|c|}
\hline $\begin{array}{c}\text { Thickness of } \\
\text { the mould } \\
\text { (mm) }\end{array}$ & $\begin{array}{c}\text { Geometry } 1 \\
\mathrm{M}=3 \text { and } \\
\mathrm{N}=1\end{array}$ & $\begin{array}{c}\text { Geometry } 2 \\
\mathrm{M}=5 \text { and } \\
\mathrm{N}=1\end{array}$ & $\begin{array}{c}\text { Geometry } 3 \\
\mathrm{M}=7 \text { and } \\
\mathrm{N}=1\end{array}$ & $\begin{array}{c}\text { Geometry } 4 \\
\mathrm{M}=9 \text { and } \\
\mathrm{N}=1\end{array}$ \\
\hline $\begin{array}{c}\text { Attenuation } \\
\left(\mathbf{m}^{-1}\right)\end{array}$ & 0,35 & 0,18 & $-0,025$ & $-0,11$ \\
\hline
\end{tabular}

\section{CONCLUSION}

The first investigations by electromagnetic modelling on the attenuation into the epoxy glass thick parts with curveshaped geometry shows that; the attenuation of energy microwaves depend the thickness and the geometry of the mould. For specific geometry this attenuation can be zero. We suggest for the next work to realize some experiences to demonstrate this solution on the think parts with epoxy glass and epoxy carbon.

\section{ACKNOWLEDGMENT}

The authors thank ministry of Science and Technology of the People's Republic of China (contract grant number 2015DFA51330) for the financial support.

\section{REFERENCES}

[1] J.P. Perez, R. Carles, R. Fleckinger ; Electromagnétisme, Fondements et applications .Masson. 3eme édition. Juillet 1990.

[2] DOUADJI L. and DELMOTTE M., Material curing by using the dielectric effect of attenuation inversion of electromagnetic waves to obtain a uniform temperature, AJAM, 3, 2006, pp. 293-296.

[3] Morey, W. U.S. Patent 3, 244, 571 (1963).

[4] Kawasa, K.; Hayakawa, K. Japon Patent 74.42522, (1974). 
[5] Ono, K.; Kitamura, M.; Shigeta, T.; Nishnura, T.; Shikuma, H. Japon . Patent 75.20984 (1975).

[6] Wilson, L. K.; Salerno, J. P. Microwave Curing of Epoxy Resins; Vanderbilt University: Nashville, TN, 1978.

[7] Jullien, H.; Delmotte, M.; Thuillier, F. M.; Valot, H.; Boulonnais, D.; Sailleau, J.; Priou, A.; Aussudre, S. Final Contract Rapport DRET, N85002, Doc. ONERA, 3/1324 MO; (1986).

[8] Aussudre, S.; Priou, A.; Jullien, H.; Delmotte, M.; Thuillier, F. M.; Boulonnais, D.; Sailleau, J. Recherche A_erospatiale, 1988, 5, 1.

[9] DOUADJI L. and DELMOTTE M., ZL 20122 034924.2, Chinese patent (2012)

[10] DOUADJI Lyes, and DELMOTTE Michel., Control of Attenuation in Microwaves Processing to Obtain Uniform Treatment of Epoxy Glass, Journal of Microwave Power and Electromagnetic Energy, 46 (3), 2012,p.176-186.

[11] DOUADJI L., WeiWei DU, Li Cheng; Compensation of microwavesource heating attenuation into the epoxy-glass composites: Experimental results; Journal of Applied Polymer, 2014.Vol. 131, Issue 8.

[12] DOUADJI L., and DU WeiWei, Shi Wen ,Claude Bathias, John Summerscales, ZL 20142 0180165.7; Chinese patent

[13] WeiWei DU, DOUADJI L., F. BENKHENAFOU, Li Cheng; A New Way to Uniform Microwave Treatment of Epoxy Glass; Materials Science Forum, Vol. 813, 2015, pp. 265-272.

[14] Thostenson, E. T.; Chou, T. W. Compos. A, 30, 1999, pp.1055. 